\title{
An Audited Experience of Therapeutic Endoscopy in Jos, Nigeria
}

\author{
Misauno M.A ${ }^{1}$, Ismaila B.O ${ }^{1}$, Ale A.F ${ }^{1}$, Isichei M.W ${ }^{1}$, Achinge G.I ${ }^{2}$ \\ Department of Surgery, Jos University Teaching Hospital ${ }^{1}$ \\ Department of Medicine, Benue State University Teaching Hospital. Makurdi. ${ }^{2}$
}

\begin{abstract}
:
Background: Therapeutic endoscopy in Nigeria is still in its infancy despite its obvious advantages of minimal access trauma, less post operative pain and shorter hospital stay. Although many gastrointestinal procedures are now being performed endoscopically, there are very few reports of experience with therapeutic endoscopy in Nigeria and the range of procedures are limited most times to upper gastrointestinal interventions. This study was aimed at auditing our experience with therapeutic endoscopy in a developing country.

Patients and methods: This was a prospective analysis of all consecutive patients with endoscopic diagnoses of oesophageal varices, benign oesophageal strictures and colorectal polyps that had injection sclerotherapy and rubber band ligation for the varices, oesophageal dilatation for strictures and snare polypectomy for the colorectal polyps.

Results: A total of 87 patients had therapeutic endoscopic interventions. Their ages ranged from 11 to $53 y$ rs with a mean age of $37.4+/-9.3 y r s$. There were 63 males and 24 females $(M: F=2.7: 1)$. Seventy patients (80.5\%) had rubber band ligation, while $8(9.2 \%)$ had injection sclerotherapy of oesophageal varices.

Six patients $(6.9 \%)$ had rectal and colonic polypectomies while three patients $(3.4 \%)$ had dilatation of benign distal oesophageal strictures. Massive upper gastrointestinal bleeding was recorded in one patient complicating injection sclerotherapy. There was no mortality in this study.

Conclusion: Therapeutic endoscopy is a safe and worthwhile method of treating gastrointestinal diseases in our environment and the types of pathologies treatable this way is bound to increase as the expertise and equipment become more widely available.
\end{abstract}

Keywords: Audit, endoscopy, Nigeria, Therapeutic

\section{Introduction}

Therapeutic endoscopy in Nigeria is still in its infancy despite its obvious advantages of minimal access trauma, less post operative pain and shorter hospital stay.(1-5) This is largely due to poor infrastructure, paucity of trained manpower, high cost of equipment and lack of political will.(6-8) Many gastrointestinal procedures are now being performed endoscopically ranging from electro-cautery and photocoagulation of bleeding lesions, rubber band ligation of oesophageal varices, through endoscopic mucosal resection of sessile lesions to cold and hot forceps methods of polypectomy.(9-10) Recently, even pancreatic necrosectomy can be carried out with the aid of upper gastrointestinal endoscopy. There are very few reports of experience with therapeutic endoscopy in Nigeria and the range of procedures are limited most times to upper gastrointestinal interventions. This is so due to lack of expertise and equipment to handle the myriads of procedures that can be carried out. This study was aimed at auditing our experience with therapeutic endoscopy in a developing country.

\section{Patients and Methods}

This study was carried out at the surgical endoscopy unit of the Jos University Teaching Hospital and the endoscopy unit of Our Lady of Apostle's Hospital (OLA) Jos. It was a prospective analysis of all consecutive patients with endoscopic diagnoses of oesophageal varices, benign oesophageal strictures and colorectal polyps from January 2003 to December 2010 who had endoscopic treatment.

Patients with oesophageal varices were offered rubber band ligation or injection sclerotherapy depending on what was available at that point in time. Benign oesophageal strictures were treated by serial dilatation while polypectomies were done for colorectal polyps.

Oesophageal variceal band ligation: After making or confirming diagnosis of oesophageal varices and assessing their suitability for banding, rubber bands were applied to the oesophageal varices using a saeed six shooter oesophageal Multi-band ligator kit (North Carolina, USA) mounted on a forward-viewing GIF P30 gastroscope (Tokyo, Japan). Patients had between 1 and 4 bands per session. Banding sessions were performed weekly until varices were obliterated.

Injection sclerotherapy: para-variceal injection of 1-3mls of sodium morrhuate was done using an endoscopic needle passed through the biopsy port of a forward-viewing gastroscope. 
Oesophageal dilatation: after visualising the stricture at endoscopy, a guidewire was passed through the biopsy port of a forward-viewing gastroscope through the stricture and into the stomach. With the guide wire in place, the gastroscope was removed and a Celestin bougie was threaded over the guide wire through the stricture to effect dilatation starting with the smallest size. Re-endoscopy confirmed success of dilatation and ruled out complications. Sessions were repeated forthnightly as was deemed necessary.

Colorectal polypectomies: the polyps were visualized and their suitability for polypectomy determined (pedunculated polyps). With the polyp in view, the endoscopic diathermy snare was introduced through the biopsy port of a colonoscope ensnaring the polyp and cauterizing it with the help of an assistant. The excised polyp was retrieved by grasping it with a biopsy forcep.

Data obtained consisted of age and sex of patients, endoscopic diagnosis, the type of intervention and outcome. Extracted data was analysed using Epi-info statistical software version.

\section{Results}

A total of 87 patients had therapeutic endoscopic interventions. Their ages ranged from 11 to $53 \mathrm{yrs}$ with a mean age of $37.4+/-9.3 y r s$. There were 63 males and 24 females $(\mathrm{M}: \mathrm{F}=2.7: 1)$

Seventy patients $(80.5 \%)$ had rubber band ligation, while $8(9.2 \%)$ had injection sclerotherapy of oesophageal varices. Forty nine patients $(70 \%)$ required 4 sessions of rubber band ligation to completely obliterate their oesophageal varices while $29(30 \%)$ had their varices obliterated after 3 sessions. All patients who had sclerotherapy required 2 sessions for complete obliteration. One patient $(1.1 \%)$ had massive upper gastrointestinal bleeding complicating injection sclerotherapy that warranted blood transfusion and open oesophageal variceal ligation.

Six patients $(6.9 \%)$ had rectal and colonic polypectomies. Five patients $(83.3 \%)$ had a single session of polypectomy while one patient $(16.7 \%)$ who presented with multiple rectal polyps required 3 sessions of polypectomy. There were no major complications with this procedure.

Three patients (3.4\%) had dilatation of benign distal oesophageal strictures. All 3 patients needed 2 sessions of dilatation each to ameliorate their dysphagia. There were no recorded complications with this treatment.

\section{Discussion}

The most commonly performed therapeutic endoscopic procedure was rubber band ligation of oesophageal varices accounting for $80.5 \%$ of the patients. This agrees with the report by Svoboda et al where oesophageal varices accounted for $72.3 \%$ of upper gastrointestinal pathologies requiring endoscopic treatment(11) but is at variance with what Gurung et al found of bleeding gastric ulcers being the most common pathology requiring endoscopic treatment.(12) This makes oesophageal varices the most commonly treated pathology endoscopic ally. This is not surprising since the facilities and training for this treatment are available to us. There were few cases of injection sclerotherapy for oesophageal varices $(9.2 \%)$ in this study. This can be explained by the proven safety of band ligation over injection sclerotherapy (13-14) making it a more acceptable procedure added to the fact that we ran out of the sclerosant at some point in the study.

Six patients had polypectomies for colon and rectal polyps. This number appears small and can be explained by the fact that our practice of colonoscopy is relatively young and restricted to resection of pedunculated polyps. We expect to be able to resect sessile polyps as the expertise increases. This is a far cry from what is obtainable in established centres where advanced endoscopic techniques are in use.(15) Three patients had serial dilatation of benign distal oesophageal strictures. These strictures from reflux oesophagitis were characteristically easier and safer to dilate even with the obsolete Celestin dilators available to us.(1619)There has been improvements in the instruments for dilatation with balloon dilators being used commonly for their safety.(20-22)

All the patients in this study were treated on day care basis except those that had oesophageal dilatation that needed admission. This could have been avoided if we had balloon dilators which are less traumatic.(5)

As more equipment and training become available, the range of procedures treated endoscopically is bound to increase.

\section{Conclusion}

Therapeutic endoscopy is a safe and worthwhile method of treating gastrointestinal diseases in our environment and the types of pathologies treatable this way is bound to increase as the expertise and equipment become more available.

\section{References}

[1]. Wright G, Lewis H, Hogan B, Burroughs A, Patch D, O'Beirne J. A self-expanding metal stent for complicated variceal hemorrhage: experience at a single center. Gastrointest Endosc. 2010 Jan;71(1):71-8.

[2]. Zubritskii VF, Zabelin MV, Sal'nikov AA, Konenkova MA, Davydov DO. [Minimal invasive treatment of bleeding of esophagus and stomach varices in patients with portal hypertension]. Eksp Klin Gastroenterol. 2010(5):48-51.

[3]. Schembre DB. Endoscopic therapeutic esophageal interventions: old, new, borrowed and ... methylene blue? Curr Opin 
Gastroenterol. 2003 Jul;19(4):394-9.

[4]. May A, Ell C. [Gastroenterological endoscopy]. Dtsch Med Wochenschr. 2011 Feb;136(5):206-8.

[5]. Youn BJ, Kim WS, Cheon JE, Kim WY, Shin SM, Kim IO, et al. Balloon dilatation for corrosive esophageal strictures in children: radiologic and clinical outcomes. Korean J Radiol. 2010 Mar-Apr;11(2):203-10.

[6]. Ogbonna BC, Obekpa PO, Momoh JT, Obafunwa JO, Nwana EJ. Laparoscopy in developing countries in the management of patients with an acute abdomen. Br J Surg. 1992 Sep;79(9):964-6.

[7]. Alatise OI, Arigbabu OA, Lawal OO, Adesunkanmi AK, Agbakwuru AE, Ndububa DA, et al. Endoscopic hemorrhoidal sclerotherapy using 50\% dextrose water: a preliminary report. Indian J Gastroenterol. 2009 Jan-Feb;28(1):31-2.

[8]. Ismaila BO, Misauno MA. Laparoscopic general surgery--the journey so far. Niger J Med. 2010 Jan-Mar;19(1):22-30.

[9]. Celinski K, Cichoz-Lach H. Therapeutic endoscopy in gastroenterology. J Physiol Pharmacol. 2007 Aug;58 Suppl 3:33-41.

[10]. Fyock CJ, Draganov PV. Colonoscopic polypectomy and associated techniques. World J Gastroenterol. 2010 Aug 7;16(29):3630-7.

[11]. Svoboda P, Ehrmann J, Klvana P, Machytka E, Rydlo M, Hrabovsky V. [A different view of acute upper gastrointestinal bleeding in liver cirrhosis patients]. Vnitr Lek. 2010 Nov;56(11):1116-21.

[12]. Gurung RB, Joshi G, Gautam N, Pant P, Pokhrel B, Koju R, et al. Upper gastro-intestinal bleeding: aetiology and demographic profile based on endoscopic examination at Dhulikhel Hospital, Kathmandu University Hospital. Kathmandu Univ Med J (KUMJ). 2010 Apr-Jun;8(30):208-11.

[13]. Siersema PD. Therapeutic esophageal interventions for dysphagia and bleeding. Curr Opin Gastroenterol. 2006 Jul;22(4):442-7.

[14]. Saeed ZA. The Saeed Six-Shooter: a prospective study of a new endoscopic multiple rubber-band ligator for the treatment of varices. Endoscopy. 1996 Sep;28(7):559-64.

[15]. Hernandez Guerrero A, Sobrino Cossio S. [Therapuetic colonoscopy]. Rev Gastroenterol Mex. 2005 Jul;70 Suppl 1:149-57.

[16]. Pregun I, Hritz I, Tulassay Z, Herszenyi L. Peptic esophageal stricture: medical treatment. Dig Dis. 2009;27(1):31-7.

[17]. Vetter S, Jakobs R, Weickert U. [Benign non-peptic esophageal stenosis: causes, treatment and outcome in routine clinical practice]. Dtsch Med Wochenschr. 2010 May;135(21):1061-6.

[18]. Qureshi S, Ghazanfar S, Leghari A, Tariq F, Niaz SK, Quraishy MS. Benign esophageal strictures: behaviour, pattern and response to dilatation. J Pak Med Assoc. 2010 Aug;60(8):656-60.

[19]. Johansson J, Oberg S, Wenner J, Zilling T, Johnsson F, von Holstein CS, et al. Impact of proton pump inhibitors on benign anastomotic stricture formations after esophagectomy and gastric tube reconstruction: results from a randomized clinical trial. Ann Surg. 2009 Nov;250(5):667-73.

[20]. Wilkinson AG, MacKinlay GA. Use of a cutting balloon in the dilatation of caustic oesophageal stricture. Pediatr Radiol. 2004 May;34(5):414-6.

[21]. Veiga C. Balloon catheter dilatation in children with esophageal stricture using a ProSeal LMA. Paediatr Anaesth. 2007 Oct;17(10):1014-5.

[22]. Cappell MS. From colonic polyps to colon cancer: pathophysiology, clinical presentation, screening and colonoscopic therapy. Minerva Gastroenterol Dietol. 2007 Dec;53(4):351-73. 